\title{
Surgical Management of Traumatic Diaphramatic Hernia in a Pup
}

\author{
M. Gokulakrishnan*, G. Mohamed Ali and Sonia \\ Department of Clinics, Madras Veterinary College, Tamil Nadu Veterinary and Animal \\ Sciences University, Chennai-600 007, India \\ *Corresponding author
}

\section{Keywords}

hunched posture, auscultation, muffled heart

Article Info

Accepted:

12 February 2020

Available Online:

10 March 2020

\section{A B S T R A C T}

A 3 month-old non-descript male pup was presented to the small animal surgery outpatient unit at madras veterinary college with a history of road traffic accident a day back. Upon presentation the dog was ambulatory, dull, and nonresponsive and exhibited a stiff gait and a hunched posture. On auscultation, muffled heart sounds were observed and dysnea was noticed due to reduction of tidal volume. The mucous membrane was pink and moist and the capillary refill time was less than 2 seconds. Excoriations on the ventral abdomen and pelvic limbs, pain on abdominal palpation and blood-tinged fluid at the preputial opening were observed in addition. Radiographs of the abdomen and thorax were taken to rule out abnormalities, if any. Abdominal radiographs showed decreased abdominal detail, a cranially shifted stomach axis and indefinitely visualized liver. Only one cupula of the diaphragm could be visualized on thoracic radiographs and ingesta was seen within the thoracic cavity. These findings were diagnostic of a traumatic diaphragmatic hernia. Hemato biochemical profile was taken to rule out organ health which revealed a stress hyperglycemia and a mildly elevated alanine aminotransferase, likely due to trauma the liver had sustained and marginal anemia with neutrophilia. All other abnormal blood parameters were consistent with the young age of the patient. The patient was maintained on a combination of oxygen, isoflurane and fentanyl as a $10 \mathrm{mg} / \mathrm{kg} \mathrm{BW}$ per hour continuous rate infusion (CRI) throughout the procedure. During episodes of hypotension the patient received $5 \mathrm{mg} / \mathrm{kg}$ BW boluses of pentastarch over $15 \mathrm{~min}$. Positive pressure ventilation was provided by a ventilator throughout the procedure. Herniorrhaphy was performed and the animal had an uneventful recovery

\section{Case history and treatment}

A 3 month-old non-descript male pup was presented to the Small Animal Surgery Outpatient Unit at Madras Veterinary College with a history of road traffic accident a day back. Upon presentation the dog was ambulatory, dull, nonresponsive and exhibited stiff gait and a hunched posture. On auscultation, muffled heart sounds were observed and dysnea was noticed due to reduction of tidal volume. The mucous membrane was pink and moist and the capillary refill time was less than 2 seconds. Excoriations on the ventral abdomen and pelvic limbs, pain on abdominal palpation and blood-tinged fluid at the preputial opening were observed in addition. Radiographs of the 
abdomen and thorax were taken to rule out abnormalities, if any. Abdominal radiographs showed decreased abdominal detail, a cranially shifted stomach axis and indefinitely visualized liver. Only one cupula of the diaphragm could be visualized on thoracic radiographs and ingesta was seen within the thoracic cavity. The decreased abdominal detail may have been due to the young age or thin body condition of the patient, but may also have been due to free fluid such as blood or urine within the abdomen. Therefore, hemoabdomen and urinary bladder rupture could not be ruled out at this stage. These findings were diagnostic of a traumatic diaphragmatic hernia. Hemato biochemical profile was taken to rule out organ health which revealed a stress hyperglycemia and a mildly elevated alanine aminotransferase, likely due to trauma the liver had sustained and marginal anemia with neutrophilia. All other abnormal blood parameters were consistent with the young age of the patient. The patient was maintained on a combination of oxygen, isoflurane and fentanyl as a 10 $\mathrm{mg} / \mathrm{kg} \mathrm{BW}$ per hour continuous rate infusion (CRI) throughout the procedure. During episodes of hypotension the patient received 5 $\mathrm{mg} / \mathrm{kg}$ BW boluses of pentastarch over 15 min. Positive pressure ventilation was provided by a ventilator throughout the procedure. Blood pressure and oxygenation status were continuously monitored using oscillometric blood pressure measurement and pulse oximetry, respectively.

The pet was preoxygenated prior to surgery at a flow rate of $50 \mathrm{ml} / \mathrm{kg} / \mathrm{min}$ using a mask. Premedication was done with diazepam and butrophenol at the dose rate of $0.5 \mathrm{mg} / \mathrm{kg}$ and $0.1 \mathrm{mg} / \mathrm{kg}$ body weight intravenously respectively. anesthesia was induced with propofol at the dose rate of $4 \mathrm{mg} / \mathrm{kg}$ body weight and maintained with isoflurane at $1.5 \%$ with oxygen as carrier gas using a open circuit. Propofol although causes significant apnea that is transient; however, when combined with diazepam lower doses of propofol can be used thereby reducing respiratory depression. A ventral mid-line incision was made from the xiphoid to the pubis. The stomach and liver were retracted from the thoracic cavity. The diaphragmatic tear consisted of a right-sided circumferential tear and a central radial tear. The circumferential tear was repaired using 2-0 polydiaxanone in a simple continuous pattern, intermittently incorporating the rib. The radial tear was also repaired with 2-0 polydiaxanone in a simple continuous pattern. Transdiaphragmatic thoracocentesis was performed to re-establish negative pressure within the thoracic cavity. The urinary bladder was examined to rule out any evidence of hemorrhageand rupture thereby hemoabdomen were ruled out. The linea alba was closed routinely using 1-0 PGA in a simple continuous pattern followed by subcutaneous tissue suturing, respectively; skin apposition was done with 2-0 polyamide in a criss cross pattern. The patient was discharged to the owner with meloxicam at the dose rate of $0.1 \mathrm{mg} / \mathrm{kg} \mathrm{BW}, \mathrm{PO}$ for $7 \mathrm{~d}$ as an anti-inflammatory, tramadol at the dose rate of $2 \mathrm{mg} / \mathrm{kg} \mathrm{BW}$, PO for $7 \mathrm{~d}$ for analgesia, and cephalexin $22 \mathrm{mg} / \mathrm{kg} \mathrm{BW}$, PO for $14 \mathrm{~d}$ for antimicrobial therapy. The patient returned to his regular active lifestyle, with no lasting effects from his trauma.

Traumatic diaphragmatic hernias occur following blunt force trauma to the abdomen causing increased abdominal pressure. When this force is combined with an open glottis, the air-filled lungs deflate, causing an increased pressure gradient across the diaphragm. This sudden pressure change across the diaphragm causes it to rupture (Worth and Machon, 2005). The weaker muscular portions of the diaphragm rupture causing tears in the direction of the muscle fibers, or tears along the attachments to the 
ribs. These are classified as radial and circumferential tears, respectively.(Garson et al., 1980). In the present case, both types of tears were present. Depending on the location of the diaphragmatic rupture certain organs herniate more frequently, with the liver being the most common. Right-sided diaphragmatic ruptures often result in small intestinal and pancreatic herniation, while left-sided diaphragmatic ruptures often result in stomach, small intestinal, and splenic herniations (Boudrieau and Muir, 1987). With the liver and stomach displaced in this case, a left-sided diaphragmatic hernia was observed routine radiography is often apprehensive to diagnose a diaphragmatic hernia as demonstrated here. Contrast radiography and ultrasonography may also be helpful. Thoracic radiographs may reveal loss of the

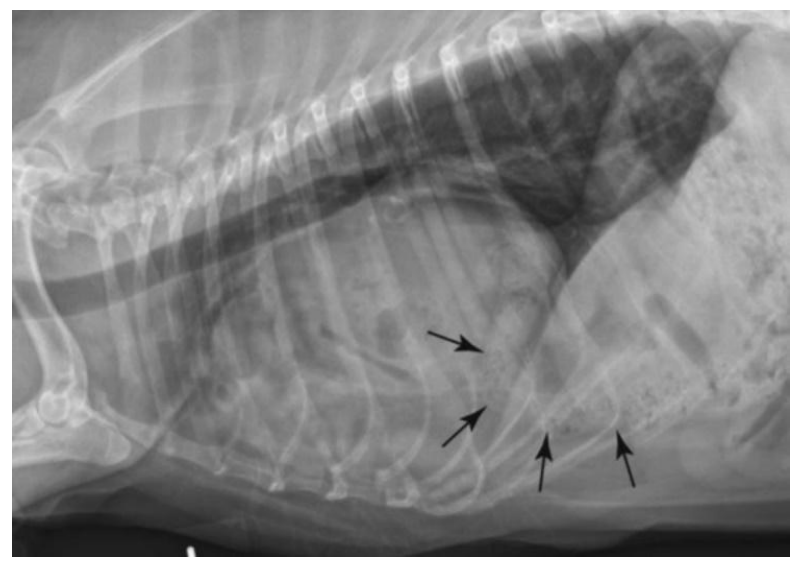

diaphragmatic contour, fluid, or air-filled viscera within the thorax, and loss of normal lung fields. Radiographs of the abdomen may reveal absence of abdominal viscera which coincided with our findings in the present case. Surgical intervention is required in all cases of traumatic diaphragmatic hernia. The timing of surgical intervention is the major variable. Allowing a trauma patient time to stabilize will make the patient more suitable for general anesthesia. Stabilization should occur over a period of $24 \mathrm{~h}$ that includes fluid resuscitation, analgesia, monitoring of blood pressure and oxygenation status, as well as any therapeutic procedures required, such as thoracocentesis, gastric decompression, and supplemental oxygenation. (Gibson et al., 2005)

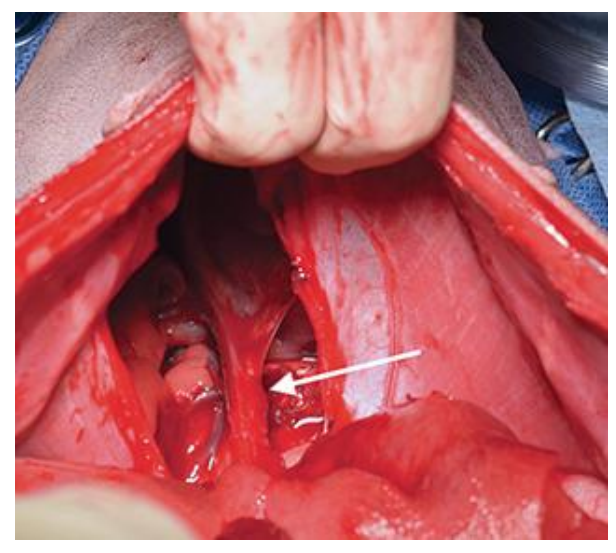

Figure.1

Mortality rates following surgical intervention for diaphragmatic herniorrhaphy vary from $6 \%$ to $20 \%$ depending on the study . It is widely accepted that surgical intervention within $24 \mathrm{~h}$ of trauma results in greater mortality; as high as $33 \%$ in one study. These patients are at a greater risk for complications of anesthesia, but with appropriate presurgical stabilization and planning, mortalities can be minimized (Schmiedt et al., 2003). Every diaphragmatic herniorrhaphy surgery should consist of diaphragmatic repair and a complete exploration of the abdomen to identify other effects of blunt force trauma such as a ruptured urinary bladder or haemoabdomen as performed in the present case needed. After surgery, patients require continuous, dedicated monitoring to assess oxygenation status and ensure pain management.

\section{References}

Boudrieau, R.J and W.WMuir. 1987. 
Pathophysiology of traumatic diaphragmatic hernia in dogs. Compend Contin EducPract Vet;9:379-385.

Garson, H., Dodman. N. and G.Baker. 1980. Diaphragmatic hernia. Analysis of fiftysix cases in dogs and cats. J Small AnimPract;21:469-481.

Gibson, T.W.G., Brisson, A.B. and W.Sears. 2005.Perioperative survival rates after surgery for diaphragmatic hernia in dogs and cats: 92 cases (1990-2002). $J$ Am Vet Med Assoc;227:105-109.
Schmiedt, C.W., Tobias, K.M and M.A.Stevenson.2003. Traumatic diaphragmatic hernia in cats: 34 cases (1991-2001). J Am Vet Med Assoc;222: 1237-1240.

Worth, A.J. and R.G. Machon. (2005). Traumatic diaphragmatic herniation: Pathophysiology and management. Compend Contin EducPract Vet;27:178-190.

\section{How to cite this article:}

Gokulakrishnan. M, G. Mohamed Ali and Sonia. 2020. Surgical Management of Traumatic Diaphramatic Hernia in a Pup. Int.J.Curr.Microbiol.App.Sci. 9(03): 1659-1662. doi: https://doi.org/10.20546/ijcmas.2020.903.194 